\title{
Grape seeds effect on refined wheat flour dough rheology: optimal amount and particle size
}

\section{Mădălina Iuga, Silvia Mironeasa}

\section{Ştefan cel Mare University of Suceava, Faculty of Food Engineering, Suceava, Romania}

\begin{tabular}{l} 
Keywords: \\
Wheat flour \\
Grape \\
Seed \\
Dough \\
Rheology \\
\hline
\end{tabular}

Article history:

Received

22.04.2019

Received in

revised form

30.09.2019

Accepted

28.11.2019

\section{Corresponding} author:

Silvia Mironeasa

E-mail:

silviam@fia.usv.ro

DOI:

$10.24263 / 2304-$

974X-2019-8-4-11

\section{Abstract}

Introduction. When developing grape seed enriched-bread, it is important to know the changes that may occur in the bread making process.

Materials and methods. The addition of different amount of grape seed flour (from 3 to $9 \%$ ) and particle size changes (large, L $>500 \mu \mathrm{m}$, medium, $200 \mu \mathrm{m}>\mathrm{M}<500 \mu \mathrm{m}$ and small fractions, $\mathrm{S}<200 \mu \mathrm{m}$ ) on the physico-chemical characteristics of the grape seeds-wheat composite flours and dough rheological behavior were investigated.

Results and discussion. The protein and ash contents increased after GSF incorporation, while the moisture and the falling number decreased depending on the particle size and addition level. The decrease of falling number values with the decrease of GSF particle size and increase the addition level indicates an increase of alpha-amylase activity in the composite flour. The storage $\left(\mathrm{G}^{\prime}\right)$, loss $\left(\mathrm{G}^{\prime \prime}\right)$, complex modulus $\left(\mathrm{G}^{*}\right)$ and loss tangent (tan $\delta$ ) of dough increased with the particle size and addition level increase. A decrease of dough maxim height $(\mathrm{Hm})$, maximum height of gaseous production $\left(\mathrm{H}^{\prime} \mathrm{m}\right)$ and total carbon dioxide volume production $(\mathrm{Vt})$ with the increase of GSF level in refined wheat flour was obtained. Gas retention coefficient $(\mathrm{Rc})$ increases with the decrease of GSF particle size. Dough fermentation parameters and dynamic rheological properties were adequately predicted by the regression models achieved. The result of optimization process showed that small particle sizes of GSF from white grape variety in an amount of $3.01 \%$ are desired to substitute refined wheat flour bread in order to ensure good rheological characteristics. Under these optimal conditions, dough fermentation characteristics and dynamic rheological properties was found to be as follows: H'm of $55.98 \mathrm{~mm}$, Vt of $1274.11 \mathrm{~mL}, \mathrm{Rc}$ of $81.22 \%, \mathrm{G}^{\prime}$ of $28.54 \cdot 10^{3} \mathrm{~Pa}, \mathrm{G}^{\prime \prime}$ of 9.79 . $10^{3} \mathrm{~Pa}, \mathrm{G}^{*}$ of $30.17 \cdot 10^{3} \mathrm{~Pa}$ and $\tan \delta$ of $345.50 \cdot 10^{-3}$.

Conclusions. This study highlights the opportunity to use grape seeds from local wine producers in order to add value to this by-product and to develop new enriched-bakery products. 


\section{Introduction}

Bakery products, especially bread are consumed all around the world. Nowadays, people turned their attention on functional foods. These are an important source of antioxidants and dietary fibers known as having benefits on human health, including cancer prevention, good cardiovascular and digestive systems functionality [1]. Manufacture of enriched fibers products is challenging since increasing the fiber content can have unfavorable effects on the product quality and consequently on the consumer acceptance. Therefore, producers need to find fiber-rich recipe with the least negative impact on the quality of the final product. Previous studies have documented the incorporation of functional ingredients from different fruit by-products, like grape pomace in bread making in order to improve nutritional value of wheat bread and to develop new functional foods [2, 3, 4]. Among grape pomace components, grape seeds represent $38-52 \%$ of grape pomace, on a dry matter basis, depending of the grape varieties [5]. Grape seeds, produced in large amounts as wine industry by-products, are more and more used to create food ingredients [6]. They contain about 10$20 \%$ lipid, $10 \%$ protein, $40 \%$ dietary fibers, sugars, minerals, polyphenolic compounds with high antioxidant activity, which may vary significantly depending on the variety of grape, location, fertilization and pedoclimatic conditions [7, 8, 9]. Grape seeds represent a valuable source of oil, characterized by higher levels of hydrophilic constituents, such as phenolic compounds, and lipophilic constituents, such as vitamin E, unsaturated fatty acids and phytosterols [10]. The amino acid composition and properties of grape seeds proteins are very similar to that of cereals. Grape seed protein is rich in glycine, glutamic acid and aspartic acid and, deficient in tryptophan and sulfur containing amino acids $[11,12]$.

Due to their chemical composition, grape seeds can be used as ingredients in various food products such as dairy [13], meat products [14], biscuits [15] and others, including wheat bread [3, 4]. As wheat flour replacement in the baking industry, the amount of GSF has a remarkable effect on bread dough. The increase of the addition level of GSF can led to an increased $\alpha$-amylase activity in the composite flour influencing dough rheological properties $[16,17,18]$. The dough behavior is also influenced by the GSF particle size which substituted wheat flour [19, 20]. GSF reduces gluten content of wheat flour resulting in technological parameters changes. Composite flour dough viscoelastic properties are different because there are some interactions of GSF components in the gluten network. There are various studies that showed the particle size influence on the chemical and physical properties of dough and on the final product quality. Higher particle size can negatively influence the bread quality because of the water absorption change and gluten network dilution by non-wheat additions [21]. The water holding capacity is higher at lower particle sizes due to the surface area augmentation [22]. The volume and the hardness of bread is strongly affected by the particle size of fibers added, so higher particle sizes leads to lower hardness and higher volume [23]. In our previous works we investigated the influence of GSF as a source of dietary fiber on the empirical and dynamic rheological characteristics of dough $[19,20,24]$. The use of large particle sizes of GSF led to significant changes of dough rheological behaviour and consequently, of the final product quality, depending of the GSF substitution level and also, on the grape variety [20]. Smaller particle sizes can be responsible for water-holding capacity increase which may enhance the starch gelatinization, protein denaturation processes, flavor and color of the product [25]. Thus, finding the appropriate addition level and particle size of GSF that can be substitute refined wheat flour (RWF) is important, in order to obtain adequate physico-chemical and rheological characteristics of composite flour and dough which would result in an acceptable bread technological quality. 
Dough stretchability and gas retention capacity, important characteristics for the final bread volume [26] can be achieved by using empirical rheological measurements conducted by means of rheofermentometer. In addition, to inform on behaviour of dough systems, the use of fundamental rheological measurements is required. The dynamic rheological properties of dough can be achieved easily using a dynamic oscillatory rheometer which simultaneously measures the elastic as well as the viscous components of dough by the application of sinusoidal oscillating strain or stress with time. This technique is useful for explaining the quality of cereal foods as well as for simulating and predicting responses to the deformation conditions that are present in practical processing but inaccessible to normal rheological measurement. Dynamic oscillatory measurements requires small amounts of sample to measure small deformational rheological changes in polymers at low strains and provides information about the fundamental structural behaviour of the material [27]. Rheological testing in the linear viscoelastic region (LVR) in order to follow the structure and properties of dough and to study the functions of dough's ingredients has been applied in various studies. The storage modulus $\left(G^{\prime}\right)$ describes the elastic character and it is in phase with the strain during oscillation. G' values of gluten dough can be a good indicator of loaf volume [28]. Dough from poor quality bread-making flour had $G^{\prime}$ values of greater magnitude then those of the good quality bread-making flour [29]. The loss modulus (G") that describes the viscous properties is out of phase [17]. The loss tangent $(\tan \delta)$, defined as the ratio of the viscous to elastic component of tested dough can be an indicator of dough elasticity, a lower value indicating a higher elasticity [30]. Complex modulus $\left(\mathrm{G}^{*}\right)$ is a factor which represent the dough strength [31], lower $\mathrm{G}^{*}$ corresponding to lower dough strength, and vice versa [32].

The aim of the present study was to investigate the influence of different GSF particle size additions at different levels in refined wheat flour on the physicochemical composition of blends, rheofermentometer characteristics and dynamic oscillatory rheological characteristics of dough and to determine the optimal formulation of GSF level-particle size addition which will give the adequate dough rheological behaviour. This information can be helpful for both bakery processors and researchers in order to predict quality of GSF enriched-bread products and to develop novel products by using locally produced grape wine pomace.

\section{Materials and methods}

\section{Basic materials}

The refined wheat flour (RWF) of 480 type (2016 harvest) was provided from S.C. Dizing S.R.L. (Brusturi, Neamt, Romania) and the grape seeds were obtained from white pomace from the viticulture center Jaristea, Odobesti ecosystem. To separate grape seeds from dried pomace the manually method was applied. Grape seed flour (GSF) resulted from seeds grinding in a domestic blender, and sieving through a Retsch Vibratory Sieve Shaker AS 200 basic (Haan, Germany) to obtain three different particle sizes: large, $\mathrm{L}>500 \mu \mathrm{m}$, medium, $200 \mu \mathrm{m}>\mathrm{M}<500 \mu \mathrm{m}$ and small fractions, $\mathrm{S}<200 \mu \mathrm{m}$.

The grape seeds presented the following analytical characteristics: moisture content 7.70\% (SR EN ISO 665:2003), fat content 18.32\% (SR EN ISO 659:2009), protein content 9.79\% (SR EN ISO 20483:2007), and ash content 2.79\% (SR ISO 2171:2009). Fiber content $(40.80 \%)$ was determined by Near Infrared Reflectance Spectroscopy (NIR). 
The flour samples were formulated from RWF and different levels of GSF $(3,5,7,9 \%)$ for each of the three particle sizes (L, M, S). The control sample was made only of RWF ( $0 \%$ GSF).

\section{Physico-chemical analysis}

The composite flours physico-chemical characteristics were determined according to the International Cereal Chemistry methods. The moisture content was performed according to ICC methods 110/1, the ash content according to ICC 104/1 method, the protein content by using the ICC 105/2 method, and the falling number was performed according to the ICC $107 / 1$ method.

\section{Rheological properties of wheat dough}

Dough fermentation characteristics. Dough rheological characteristic during fermentation were assessed by using the Chopin Rheofermentometer F3 (Chopin Rheo, Villeneuve-LaGarenne Cedex, France). Mixing was performed in a Brabender Farinograph for $8 \mathrm{~min}$ at $30^{\circ} \mathrm{C}$ from $250 \mathrm{~g}$ flour blend, $7 \mathrm{~g}$ compressed yeast, $5 \mathrm{~g}$ salt and water according to the Farinograph water absorption. The dough $(315 \mathrm{~g})$ was tested at $30^{\circ} \mathrm{C}$ for $3 \mathrm{~h}$ under a $2000 \mathrm{~g}$ cylindrical weight constraint. The fermentation characteristics of dough development determined for the formulated samples (Table 1) shows maximum dough maximum height $(\mathrm{Hm})$, maximum height of gaseous production ( $\left.\mathrm{H}^{\prime} \mathrm{m}\right)$, total carbon dioxide volume production (Vt) and gas retention coefficient (Rc).

Dynamic rheological measurement. Dough dynamical rheological properties were achieved using MARS 40 rheometer (Thermo-Haake, Karlsruhe, Germany) equipped with titanium parallel plate geometry (diameter $40 \mathrm{~mm}$ ). The water needed for dough formulation at optimum consistency was previously established by the farinographic method, based on the water absorption value, for each composite flour formulation. The samples were placed between the parallel plates at $2 \mathrm{~mm}$ gap and the excess dough was removed. A thin layer of vaseline was spread to the exposed dough side to prevent water evaporation during measurement. A period of 5 min of rest between plates was established for each sample before test to allow relaxation and stabilize temperature. All the measurements were performed at $20.0 \pm 0.1^{\circ} \mathrm{C}$. Before to perform the frequency sweep test, the linear viscoelastic region of the sample was established based on the strain sweep tests, increasing strain from 0.01 to $100 \mathrm{~Pa}$, at constant oscillation frequency of $1 \mathrm{~Hz}$. Frequency sweep tests were conducted in the oscillation frequency of 1 to $20 \mathrm{~Hz}$ and at shear stress of $15 \mathrm{~Pa}$. The rheological behavior was evaluated by the storage modulus G' (Eq. 1), the loss modulus G" (Eq. 2), loss tangent (Eq. 3) and complex shear modulus $G^{*}$ (Eq. 4) variation with frequency [33]:

$$
\begin{gathered}
G^{\prime}=\left(\frac{\sigma_{0}}{\gamma_{0}}\right) \cos (\delta) \\
G^{\prime \prime}=\left(\frac{\sigma_{0}}{\gamma_{0}}\right) \sin (\delta) \\
\tan \delta=\frac{G^{\prime \prime}}{G^{\prime}} \\
G^{*}=\sqrt{\left(G^{\prime}\right)^{2}+\left(G^{\prime \prime}\right)^{2}}
\end{gathered}
$$

where $\sigma_{0}$ is constant shear stress $(\mathrm{Pa}), \gamma_{0}$ is constant shear strain and $\delta$ is phase angle (rad). 


\section{Experimental design and statistical analysis}

The combination effects of two factors, addition level (A) in RWF at five levels $(0,3,5$, 7, 9\%) and particle size (B) at 3 levels (L, M, S) for the GSF on the rheofermentometer characteristics (Hm, H'm, Vt and Rc) and the dynamic rheological characteristics (G', G", $\mathrm{G}^{*}, \tan \delta$ ) of the composite flour dough as responses were investigated using response surface methodology (RSM) by means of general factorial design. The experimental design with real and coded factors values which led to 15 runs of experiments is shown in Table 1.

Table 1

Coded and real values of formulations factors

\begin{tabular}{|c|c|c|c|c|}
\hline \multirow{2}{*}{ Run } & \multicolumn{2}{|c|}{ Coded values } & \multicolumn{2}{c|}{ Real values } \\
\cline { 2 - 5 } & A & B & $\begin{array}{c}\text { GSF } \\
(\%)\end{array}$ & Particle size $(\boldsymbol{\mu m})$ \\
\hline 1 & 0.111 & -1.000 & 5.000 & 200 \\
\hline 2 & 1.000 & 1.000 & 9.000 & 600 \\
\hline 3 & 1.000 & 0.000 & 9.000 & 400 \\
\hline 4 & 0.556 & -1.000 & 7.000 & 200 \\
\hline 5 & 0.111 & 1.000 & 5.000 & 600 \\
\hline 6 & -1.000 & 0.000 & 0.000 & 400 \\
\hline 7 & 0.556 & 0.000 & 7.000 & 400 \\
\hline 8 & -0.333 & 1.000 & 3.000 & 600 \\
\hline 9 & -1.000 & 1.000 & 0.000 & 600 \\
\hline 10 & -1.000 & -1.000 & 0.000 & 200 \\
\hline 11 & -0.333 & -1.000 & 3.000 & 200 \\
\hline 12 & 1.000 & -1.000 & 9.000 & 400 \\
\hline 13 & -0.333 & 0.000 & 3.000 & 400 \\
\hline 14 & 0.11 & 0.000 & 5.000 & 600 \\
\hline 15 & 0.556 & 1.000 & 7.000 & \\
\hline
\end{tabular}

To the established predictive models for rheological characteristics, experimental results for each response variable were fitted to polynomial quadratic regression equation (Eq. 1):

$$
\mathrm{Y}=\mathrm{b}_{\mathrm{o}}+\mathrm{b}_{1} \times \mathrm{X}_{1}+\mathrm{b}_{2} \times \mathrm{X}_{2}+\mathrm{b}_{11} \times \mathrm{X}_{1}^{2}+\mathrm{b}_{22} \times \mathrm{X}_{2}^{2}+\mathrm{b}_{12} \times \mathrm{X}_{1} \times \mathrm{X}_{2}
$$

where, $\mathrm{Y}$ is the response variable, $\mathrm{b}_{\mathrm{o}}, \mathrm{b}_{1}, \mathrm{~b}_{2}, \mathrm{~b}_{11}, \mathrm{~b}_{22}$ and $\mathrm{b}_{12}$ - regression coefficients for intercept, linear, quadratic and interaction effects respectively of $\mathrm{X}_{1}$ and $\mathrm{X}_{2}$ independent variables (addition level and particle size of grape seeds flour).

The multiple linear regression analysis was applied to fit the results obtained for each response to linear, quadratic and cubic models and the most adequately predictive model was chosen through sequential $F$-test, coefficients of determination $\left(R^{2}\right)$, adjusted coefficients of determination $\left(A d j .-R^{2}\right)$, and significant probabilities. In order to determine the validity of the model for each response, the experimental and predictive values were compared by paired $\mathrm{t}$ test $(p<0.05)$. Analysis of variance (ANOVA) was carried out to evaluate the statistical significance of the coefficients in each model. The polynomial response surfaces were generates showing the combined effect of the factors, addition level and particle size of the 
GSF on the response variables, dough rheological characteristics during fermentation and dynamic rheological characteristics.

Stat-Ease Design-Expert 7.1 software (trial version) was employed to carry out the experimental design, the model adequacy testing, response surface plots generation and the optimum level of formulation factors finding. In order to find the optimal value of the factors, level and particle size for the GSF added in RWF, the multiple responses analysis was applied to predictive models fitted. For the optimization, each predicted response is transform into an individual desirability function, $\mathrm{d}_{\mathrm{n}}$ which comprise the desired and researcher's priorities when building the optimization procedure for each of the factors. The individual desirability functions are then combined into a single composite response, named overall desirability function, D computed as the geometric mean of the individual desirability function, $d_{n}$ which varies from 0 to 1 [34]. For the numerical optimization, the minimum particle size of grape seeds flour, as factor, maximum for dough maximum height, maximum gas retention coefficient, minimum for complex viscosity and loss tangent, as responses were selected.

The statistical analysis of data reported for physico-chemical characteristics was performed by using SPSS software (13.0 version) and the results were expressed as mean value with the standard deviation. The multivariate analysis and the post-hoc multiple comparisons with Tukey test at a 95\% confidence level was used in order to detect statistical difference. Observed factors were addition level and particle size.

\section{Results and discussion}

\section{Physico-chemical characteristics}

The size reduction of GSF has a significant influence on the physico-chemical characteristics of the composite flours (Table 2). The moisture, ash and protein contents were significantly different $(p<0.05)$ among the samples with different addition levels of GSF and particle sizes. The moisture level decreased after GSF addition compared to the control and increased with the decrease of the particle size, except for 3\% addition level. A similar decreasing trend of the moisture content with the size reduction has been reported for the rye and barley flours [35]. The ash content increase with the addition level increase and with the particle size decrease can be related to the mineral content of GSF [36, 67], significant differences $(p<0.05)$ being observed among all the analyzed samples (Table 2 ).

An increase of the protein content of the samples with GSF was observed with the increase of the addition level and the particle size decrease, as a result of the protein content of GSF [8] which is substantially influenced by the sieving. The highest protein content of composite flour with small particle size (S) could indicate that some parts of the grape seeds, richer in proteins, were broken into small particles. A similar increase of the protein content with the particle size decrease has been reported for soy flour [38].

The falling number value inform on the alpha-amylase activity of the composite flour [39]. The addition of GSF decreased the falling number values compared to the control which means an increase of the alpha-amylase activity as a result of the calcium content increase induced by GSF which is mineral-rich $[8,37]$. It is known that alpha-amylase is a metalloenzyme which depends on the presence of metal ions calcium in its molecule for its activity [40]. 
Influence of the formulation factors on the physico-chemical characteristics of the composite flours

\begin{tabular}{|c|c|c|c|c|c|}
\hline \multicolumn{2}{|c|}{ Factor } & \multirow{2}{*}{$\begin{array}{c}\text { Moisture } \\
(\%)\end{array}$} & \multirow{2}{*}{$\begin{array}{l}\text { Ash } \\
(\%)\end{array}$} & \multirow{2}{*}{$\begin{array}{c}\text { Protein } \\
(\%)\end{array}$} & \multirow{2}{*}{$\begin{array}{c}\text { Falling number } \\
\text { (s) }\end{array}$} \\
\hline GSF (\%) & Particle size & & & & \\
\hline 0 & 0 & $14.10 \pm 0.00^{\mathrm{a}}$ & $0.47 \pm 0.00^{\mathrm{a}}$ & $10.80 \pm 0.00^{\mathrm{a}}$ & $370.50 \pm 11.50^{\mathrm{a}}$ \\
\hline 3 & $\mathrm{~L}$ & $13.25 \pm 0.05^{\mathrm{bx}}$ & $0.68 \pm 0.00^{\mathrm{bx}}$ & $10.90 \pm 0.00^{\mathrm{bx}}$ & $369.00 \pm 10.00^{\text {cy }}$ \\
\hline 3 & $\mathrm{M}$ & $13.06 \pm 0.01^{\mathrm{bz}}$ & $0.75 \pm 0.00^{\text {by }}$ & $10.95 \pm 0.05^{\text {by }}$ & $351.50 \pm 12.50^{\mathrm{cx}}$ \\
\hline 3 & $\mathrm{~S}$ & $12.98 \pm 0.02^{\text {by }}$ & $0.80 \pm 0.00^{\mathrm{bz}}$ & $11.05 \pm 0.05^{\mathrm{bz}}$ & $346.00 \pm 14.00^{\mathrm{cx}}$ \\
\hline 5 & $\mathrm{~L}$ & $12.87 \pm 0.03^{\mathrm{cx}}$ & $0.71 \pm 0.00^{\mathrm{cx}}$ & $10.93 \pm 0.03^{\mathrm{cx}}$ & $368.00 \pm 6.00^{\text {bcy }}$ \\
\hline 5 & $\mathrm{M}$ & $12.98 \pm 0.02^{\mathrm{cz}}$ & $0.86 \pm 0.01^{\mathrm{cy}}$ & $11.10 \pm 0.10^{\text {cy }}$ & $346.00 \pm 4.00^{\mathrm{bcx}}$ \\
\hline 5 & $\mathrm{~S}$ & $13.10 \pm 0.01^{\text {cy }}$ & $0.95 \pm 0.01^{\mathrm{cz}}$ & $11.30 \pm 0.00^{\mathrm{cz}}$ & $343.00 \pm 13.00^{\mathrm{bcx}}$ \\
\hline 7 & $\mathrm{~L}$ & $12.85 \pm 0.01^{\mathrm{dx}}$ & $0.72 \pm 0.00^{\mathrm{dx}}$ & $11.00 \pm 0.01^{\mathrm{dx}}$ & $365.00 \pm 7.00^{\text {bcy }}$ \\
\hline 7 & $\mathrm{M}$ & $12.98 \pm 0.02^{\mathrm{dz}}$ & $0.95 \pm 0.02^{\mathrm{dy}}$ & $11.15 \pm 0.05^{\mathrm{dy}}$ & $345.50 \pm 5.50^{\mathrm{bcx}}$ \\
\hline 7 & $\mathrm{~S}$ & $12.86 \pm 0.04^{\mathrm{dy}}$ & $1.08 \pm 0.00^{\mathrm{dz}}$ & $11.50 \pm 0.04^{\mathrm{dz}}$ & $341.00 \pm 15.00^{\mathrm{bcx}}$ \\
\hline 9 & $\mathrm{~L}$ & $12.39 \pm 0.03^{\mathrm{ex}}$ & $1.05 \pm 0.01^{\mathrm{ex}}$ & $11.25 \pm 0.07^{\mathrm{ex}}$ & $349.00 \pm 7.00^{\text {by }}$ \\
\hline 9 & $\mathrm{M}$ & $12.85 \pm 0.02^{\mathrm{ez}}$ & $1.07 \pm 0.01^{\mathrm{ey}}$ & $11.35 \pm 0.05^{\mathrm{ey}}$ & $336.50 \pm 8.50^{\mathrm{bx}}$ \\
\hline 9 & $\mathrm{~S}$ & $12.72 \pm 0.06^{\mathrm{ey}}$ & $1.26 \pm 0.00^{\mathrm{ez}}$ & $11.69 \pm 0.05^{\mathrm{ez}}$ & $334.00 \pm 11.00^{\mathrm{bx}}$ \\
\hline
\end{tabular}

GSF particle sizes: Large, $\mathrm{L}>500 \mu \mathrm{m}$, Medium, $200 \mu \mathrm{m}>\mathrm{M}<500 \mu \mathrm{m}$ and Small fractions, $\mathrm{S}<200$ $\mu \mathrm{m}$. The results are expressed as mean values of triplicates ( \pm standard deviation). Mean values are followed by different superscript (a-e) in the same column (GSF at 0, 3, 5, 7, 9\% addition levels) if there are significantly different, according to Turkey's test $(p<0.05)$; $\mathrm{x}-\mathrm{z}$ for the same addition level of GSF and different particle sizes (L, M and S), means in the same column with different superscript were significantly different $(p<0.05)$.

High alpha-amylase activity leads to an improved bread quality in terms of color, volume and texture [41]. Significant differences $(p<0.05)$ of the falling number values were observed between the control and all samples and between sample with 3\% GSF and all others. Similar results were obtained when wheat flour was replaced with grape seed flour from two varieties at different levels [20]. Significant differences $(p<0.05)$ of the falling number values were also obtained between the large (L) particle size and control, small (S) and medium (M) particle size, respectively (Table 2).

\section{Effects of GSF addition level and particle size on dough fermentation characteristics}

As shown in Table 3, the quadratic model was found to represent adequately the data for the dough maximum height $(\mathrm{Hm})$ as a function of the formulation factors, the $R^{2}$ value $(0.92)$ confirming the adequacy of the model. The linear coefficient of the addition level of GSF indicates a significant negative influence on the $\mathrm{Hm}$, while the linear term of particle size has a significant positive effect. Hm was significantly correlated $(p<0.05)$ with the interaction effect of GSF addition level in RWF and particle size. The effect of GSF addition level and particle size can be seen in Figure 1a, indicating an increase in $\mathrm{Hm}$ with particle size increase. The negative coefficient of GSF addition level indicated that the $\mathrm{Hm}$ of the composite flour decreased with the increase of GSF addition level in RWF. This decrease may be attributed to the gluten dilution as a result of an addition of non-gluten flour [42]. The high level of GSF added in the gluten matrix may introduce physical interruption which can cause dough weakening. Lower Hm indicates that the gas resulted from the fermentation process and the microstructure of a system were not able to sustain the macrostructure of the proofed dough piece. Unfavorable, final product volume is expected when the gas retention is not efficient. Hm decreased as the level increased (Figure 1a) and the GSF level effect was higher than the one of particle size (Table 3). 
Table 3

Effects of formulation factors, expressed as their corresponding coefficients in the predictive models for dough fermentation characteristics and dynamic rheological characteristics ${ }^{\text {a }}$

\begin{tabular}{|c|c|c|c|c|c|c|c|c|}
\hline \multirow{3}{*}{ Factors ${ }^{b}$} & \multicolumn{8}{|c|}{ Characteristics } \\
\hline & \multicolumn{4}{|c|}{ Rheofermentometer } & \multicolumn{4}{|c|}{ Dynamic rheological } \\
\hline & $\begin{array}{c}\mathbf{H m} \\
(\mathbf{m m})\end{array}$ & $\begin{array}{c}\text { H'm } \\
(\mathbf{m m})\end{array}$ & $\begin{array}{c}\mathbf{V t} \\
(\mathbf{m L})\end{array}$ & $\begin{array}{l}\text { Rc } \\
(\%)\end{array}$ & $\begin{array}{c}\mathbf{G}^{\prime}\left(10^{3}\right) \\
(\mathbf{P a})\end{array}$ & $\begin{array}{c}\mathrm{G}^{\prime \prime}\left(10^{3}\right) \\
(\mathrm{Pa})\end{array}$ & $\begin{array}{c}*\left(10^{3}\right) \\
(\mathrm{Pa})\end{array}$ & $\begin{array}{l}\tan \delta \\
\left(10^{-3}\right)\end{array}$ \\
\hline $\begin{array}{l}\text { Constan } \\
\mathrm{t}\end{array}$ & 38.86 & 56.74 & 1252.00 & 81.22 & 25.89 & 8.69 & 27.31 & 340.00 \\
\hline $\mathrm{A}$ & $-6.66^{* * * *}$ & $-6.34^{* * * *}$ & $-57.93^{* * * *}$ & $-0.44^{*}$ & $11.37^{* * * *}$ & $3.66^{* * * *}$ & $11.94^{* * *}$ & $-8.29^{* * * *}$ \\
\hline $\mathrm{B}$ & $5.12^{* * *}$ & $4.27^{* * *}$ & 2.83 & 0.52 & $-6.15^{* * *}$ & $-2.12^{* * *}$ & $-6.51^{* * *}$ & $-3.44^{*}$ \\
\hline $\mathrm{A} \times \mathrm{B}$ & $4.07^{* * *}$ & $3.07^{* *}$ & $17.61^{*}$ & $0.75^{*}$ & $-9.46^{* * * *}$ & $-3.14^{* * * *}$ & $-9.97^{* * * *}$ & - \\
\hline $\mathrm{A}^{2}$ & 0.79 & 0.84 & - & $-2.13^{* *}$ & 1.94 & $0.73^{*}$ & 2.08 & - \\
\hline $\mathrm{B}^{2}$ & -0.23 & 0.34 & - & 0.35 & $3.16^{*}$ & $1.14^{*}$ & $3.36^{*}$ & - \\
\hline$R^{2}$ & 0.92 & 0.92 & 0.51 & 0.78 & 0.88 & 0.89 & 0.89 & 0.44 \\
\hline Adj. $-R^{2}$ & 0.88 & 0.87 & 0.38 & 0.65 & 0.82 & 0.83 & 0.82 & 0.35 \\
\hline$p$-value & $\begin{array}{c}< \\
0.0001\end{array}$ & $\begin{array}{c}<< \\
0.0001\end{array}$ & $<0.05$ & $<0.01$ & $<0.001$ & $<0.001$ & $<0.001$ & $<0.05$ \\
\hline
\end{tabular}

$\mathrm{a}^{*} \mathrm{p}<0.5 ;{ }^{* *} \mathrm{p}<0.05 ;{ }^{* * *} \mathrm{p}<0.005$

${ }^{\mathrm{b}} A$, grape seeds flour level added in white wheat flour $(\%) ; B$, grape seeds flour particle size $(\mu \mathrm{m}) ; R^{2}$, Adj. $-R^{2}$ are measures of model fit; $H m$, dough maximum height; $H^{\prime} m$, maximum height of gaseous production; $V t$, total carbon dioxide volume production; $R c$, gas retention coefficient; $G^{\prime}$, storage modulus; $G^{\prime \prime}$, viscous modulus; $G^{*}$, complex modulus; $\tan \delta$, loss tangent

The maximum height of gaseous production ( $\left.\mathrm{H}^{\prime} \mathrm{m}\right)$, a critical parameter of the fermentation process was significantly $(\mathrm{p}<0.0001)$ influenced by the particle size and the level of GSF addition in RWF (Table 3). The $R^{2}(0.92)$ and $A d j .-R^{2}(0.87)$ values showed that the quadratic regression model fitted to the experimental results of H'm characteristics showed higher $R^{2}$ value (0.92). The linear term of GSF level, particle size and the interaction term showed a significant effect on H'm. The addition level has a negative effect on H'm, whereas particle size has a positive effect. A negative effect on H'm can be due to the disruption of the starch-gluten matrix from the composite flour which restricts and forces gas cells to expand in a particular dimension influencing gassing power of dough. The effect of GSF level and particle size added in RWF on the H'm is shown in Figure 1b. Response surface plot showed that an increased level of GSF added in RWF increased the maximum height of gaseous production. The H'm was mostly affected by the addition level. The high level of GSF does not allow the increase of the gas production during dough fermentation. 


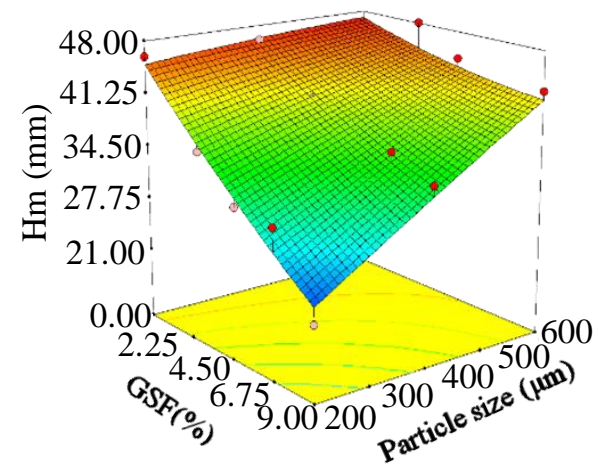

(a)

Figure 1. Response surface plot showing the combined effects of grape seeds flour (GPF) level and particle size of GPF on: (a) dough maximum height $(\mathrm{Hm})$ and

(b) maximum height of gaseous production $\left(\mathrm{H}^{\prime} \mathrm{m}\right)$

The factors GSF addition level in RWF and the particle size affected the total carbon dioxide volume production $(\mathrm{Vt})$ significantly $(p<0.05)$ (Table 3$)$. A two-factor interaction $(2 \mathrm{FI})$ regression model for Vt showed a significant effect $(p<0.05)$ in linear term of GSF level, while the linear term of particle size was non-significant $(p>0.05)$. The ANOVA results showed that the regression model obtained was an adequately one with a good $R^{2}$ value of 0.51 . The negative effect of GSF addition level on Vt can be related to the disruption of the gluten network when the GSF are incorporated in dough matrix. At the large particle size, Vt increased as the particle size increased, but the particle size effect was lower than the one of the level of GSF added in RWF. This effect can be explained by the bioactive compounds from GSF which influenced yeast activity, having an essential effect on $\mathrm{CO}_{2}$ production. The effect of GSF level and particle size added in RWF on Vt is shown in Figure 2a. The response surface obtained showed that the increase of GSF level decreased Vt parameter.
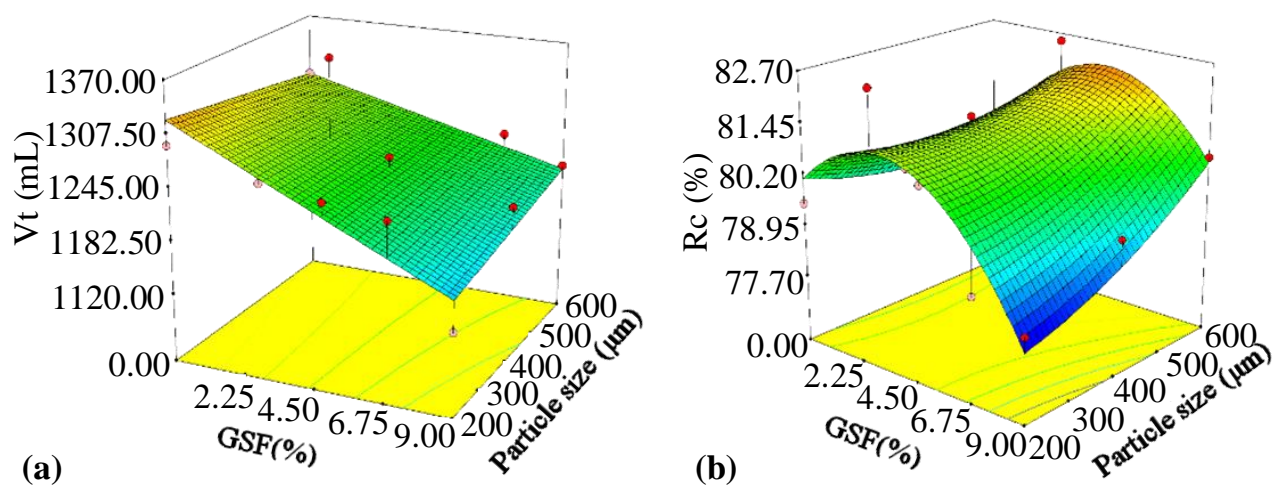

Figure 2. Response surface plot showing the combined effects of grape seeds flour (GPF) level and particle size of GPF on: (a) total carbon dioxide volume production (Vt) and (b) gas retention coefficient $(\mathbf{R c})$ 
The gas retention coefficient $(\mathrm{Rc})$ defined as the retention volume divided by the total gaseous release, was significantly $(p<0.01)$ influenced by the level of GSF addition in RWF. The high value of $R^{2}(0.78)$ indicates that the quadratic model is a good prediction model of Rc using the significant factors shown in Table 3. GSF level shows negative influences on $\mathrm{Rc}$ while the particle size was non-significant $(p>0.05)$. Also, the quadratic term of GSF addition level was found to have a significant negative effect on Rc. A response surface plot, showing the effect of GSF level and particle size on Rc, is represented in Figure 2b. As it can be seen, the Rc significantly decreased as the GSF addition level increased. This behaviour is probably due to the increase of the osmotic pressure on the yeast cells, which can lead to an inhibitory effect on the yeast metabolism. In addition, the interactions between gluten and the fraction from GSF, especially fibrous, may prevent the free expansion of dough during proofing. Furthermore, fibers can cause a breakdown of the gluten protein matrix, acting as points of weakness within the expanding dough cell walls [19].

\section{Effects of GSF addition level and particle size on dough dynamic rheological characteristics}

The effect of GSF addition level and particle size as structural ingredients can be revealed through oscillatory measurements. By measuring the storage or elastic modulus $\left(\mathrm{G}^{\prime}\right)$ different resistance to the rupture by the action of stress on the dough formulation structures can be assessed. GSF addition level has significant effect on the $\mathrm{G}^{\prime}$ through the linear positive effect. The effect of GSF addition level on G' was counteracted by the negative linear term of particle size (Table 3). The interaction between both factors have a negative significant $(p<0.01)$ effect on $\mathrm{G}^{\prime}$ modulus. The regression model fitted to the experimental results o dough elastic modulus showed higher coefficient of determination $\left(R^{2}=0.88\right)$. The $F$-value for $\mathrm{G}^{\prime}$ was significant $(p<0.001)$. The effects of the addition level and particle size on $\mathrm{G}^{\prime}$ are shown in Figure 3a. Response surface plot showed that an increase of GSF level added in RWF increases G' modulus. The increase could be explained by the GSF compounds which can act in dough as filler that reinforces the gluten and produces strong bonds to give higher modulus. Similar results were obtained by Sivaramakrishnan et al. [43] for rice-wheat composite dough.

(a)
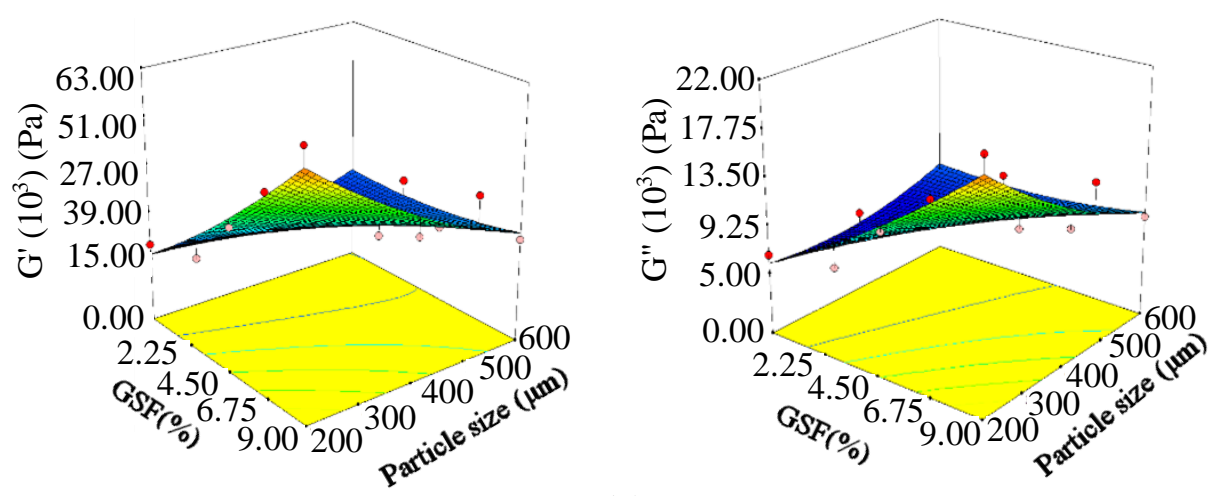

(b)

Figure 3. Response surface plot showing the combined effects of grape seeds flour (GPF) level and particle size of GPF on: (a) storage modulus (G') and (b) viscous modulus (G") 
The viscous modulus $\left(G^{\prime \prime}\right)$ was influenced by the presence of GSF levels and particle sizes added in RWF, which had a significant $(p<0.005)$ effect (Table 3$)$. $G^{\prime \prime}$ was positively influenced by the addition level and negatively by the particle size and the interaction between them. The quadratic regression model obtained for $G^{\prime \prime}$ indicates high correlation coefficient ( 0.89$)$, statistically significant at $p<0.001$, revealed that this model is a predictive one. As it can be seen in Figure 3b, the response surface plot showed a decrease of $G^{\prime \prime}$ as the level of GSF added in RWF increased. These variations could be attributed to the differences of lipid, protein, fiber constituents of grape seeds flour, shape and size of starch granules of wheat flour [44]. The proportionality of $G^{\prime \prime}$ increase with the addition level is probably due to the different soluble and insoluble fractions ratio, higher water absorption can be linked to the higher amount of fibers from GSF [45], which leads to an increased viscosity. The viscous modulus, $G^{\prime \prime}$ values are smaller than those of the elastic modulus, $G^{\prime}$, indicating that the composite flours formulations have a good quality which can lead to higher bread loaf volume [46].

The complex modulus $\left(G^{*}\right)$, as a good indicator of total resistance to deformation of dough, was significantly influenced $(p<0.001)$ by the level and particle size of GSF added in RWF. The ANOVA results showed that the addition level had a significant positive influence $(p<0.005)$ on $G^{*}$, but the particle size and the interaction between them have a negative one $(p<0.005)$ (Table 3$)$. The quadratic model is statistically significant $(p<0.001)$ and the value of the determination coefficient $\left(R^{2}=0.89\right)$ indicates that only $11 \%$ of the total variations in the response is not explained by the model. The factors effects are shown in Figure 4a). GSF addition level increase and particle size decrease determined an increase of $G^{*}$, showing an increase of dough consistency, probably as a result of GSF water absorption capacity. The amount of insoluble fibers from GSF may be responsible for this increase because the addition of fibers in dough makes his structure stiffer. Similar results were reported by Ahmed [47] who evaluated dough with $\beta$ glucan addition.

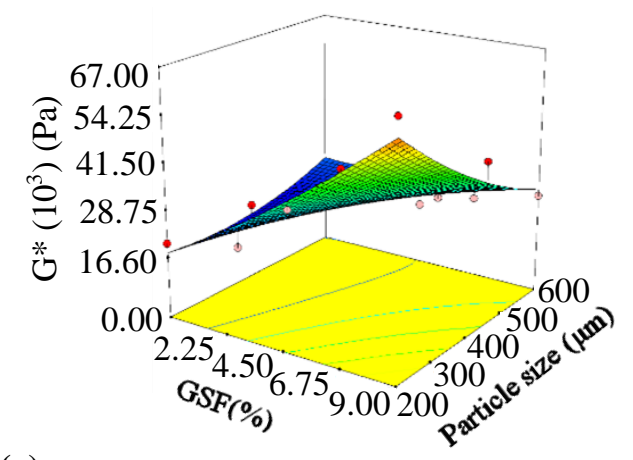

(a)

Figure 4. Response surface plot showing the combined effects of grape seeds flour (GPF) level and particle size of GPF on: (a) complex modulus $\left(G^{*}\right)$ and (b) loss tangent (tan $\left.\delta\right)$

The loss tangent or phase angle $(\tan \delta$ ) inform on the phase shift between the stress and strain in oscillation. This characteristics, determined as the ratio of the viscous to the elastic properties of the material, at frequency of $1 \mathrm{~Hz}$, was significantly $(p<0.005)$ influenced by GSF level added in RWF, but the linear coefficient of particle size has not significant effect on $\tan \delta$ (Table 3). The response surface plot (Figure 3b) indicated an increase of the total resistance to deformation of dough with GSF level increase in RWF. These increase, can be 
due to the high content of fiber of GSF, especially insoluble fibre, which substitute RWF, knowing that the dough with fiber enrichment formed stiffer structure than the wheat sample [48]. Insoluble fiber compounds of GSF can interact with the gluten matrix trough hydrogen bonds rising dough stiffness or acting as filler in the viscoelastic matrix.

\section{Optimal particle size and grape seeds flour addition level in refined wheat flour}

The optimization was based on the models fitted above for each response and was made by applying the desirability function. In order to improve dough machinability, especially in composite flour dough with different GSF of different particle size, dough rheology is essential. In order to perform simultaneously optimization of multiple responses, some constrains such as $\mathrm{Vt}$ and $\mathrm{Rc}$ were desired maximal, whereas $\mathrm{G}^{*}$ and $\tan \delta$ were specified as minimum. The results for the optimization revealed that composite flour based on RWF containing 3.01\% of GSF of $200 \mu \mathrm{m}$ particle size could be a good one to achieve the best grape seed-wheat composite flour bread quality. The interactions between dough system's components can change his characteristics due to the macromolecular organization, thus smaller GSF quantity and smaller particle size can lead to better bread quality. The desirability ramp developed for the optimized conditions is shown in Figure 5, revealing an overall desirability value of 0.54 .

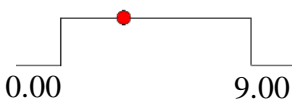

$\operatorname{GSF}(\%)=3.01$

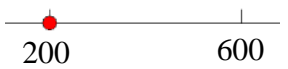

Particle size $(\mu \mathrm{m})=200$

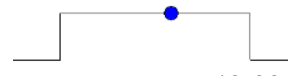

21.50 48.00
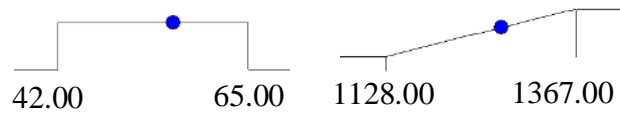

$1128.00 \quad 1367.00$

$\mathrm{Vt}(\mathrm{mL})=1274.11$

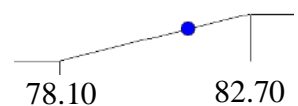

$\operatorname{Rc}(\%)=81.22$

$\operatorname{Hm}(\mathrm{mm})=37.14 \quad \mathrm{H}^{\prime} \mathrm{m}(\mathrm{mm})=55.98$
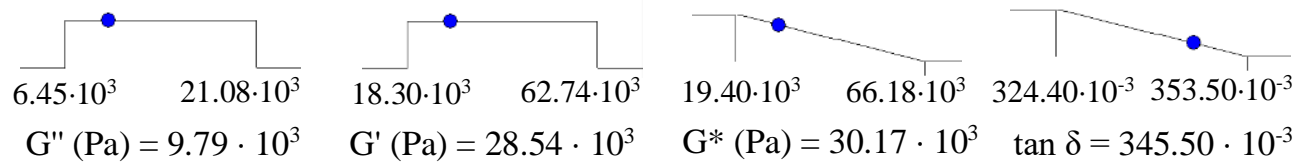

$\mathrm{G}^{*}(\mathrm{~Pa})=30.17 \cdot 10^{3}$

$324.40 \cdot 10^{-3} 353.50 \cdot 10^{-3}$

Figure 5. Desirability ramp for optimization process

Under these optimal amount and particle size of grape seed flour addition in refined wheat flour, the values predicted for each response in terms of dough fermentation characteristics and dynamic rheological properties was found to be as follows: dough maximum height, $\mathrm{Hm}$ of $37.14 \mathrm{~mm}$, maximum height of gaseous production, $\mathrm{H}$ 'm of 55.98 $\mathrm{mm}$, total carbon dioxide volume production, $\mathrm{Vt}$ of $1274.11 \mathrm{~mL}$, gas retention coefficient, Rc of $81.22 \%$, elastic modulus $\mathrm{G}^{\prime}$ of $28.54 \cdot 10^{3} \mathrm{~Pa}$, viscous modulus, G" of $9.79 \cdot 10^{3} \mathrm{~Pa}$, complex modulus, $\mathrm{G}^{*}$ of $30.17 \cdot 10^{3} \mathrm{~Pa}$ and loss tangent, $\tan \delta$ of $345.50 \cdot 10^{-3}$. 


\section{Model validation}

The obtained models of dough fermentation characteristics and dynamic rheological properties were verified by comparing the predicted data with the experimental data. The data obtained at the optimal value of factors, the amount of GSF added (3.01\%) and particle size (small) for each response studied confirms that the optimization was made accurately being close to the predicted values (Table 4).

Table 4

Predicted versus experimental values at the optimal amount and particle size of grape seeds flour addition in refined wheat flour

\begin{tabular}{|l|c|c|c|}
\hline \multirow{2}{*}{ Parameters } & \multicolumn{3}{|c|}{ Values } \\
\cline { 2 - 4 } & Predicted & Experimental & SE Mean \\
\hline $\mathrm{Hm}(\mathrm{mm})$ & 37.14 & 37.17 & 1.37 \\
\hline $\left.\mathrm{H}^{\prime} \mathrm{(mm}\right)$ & 55.98 & 56.01 & 1.25 \\
\hline $\mathrm{Vt}(\mathrm{mL})$ & 1274.11 & 1274.35 & 21.98 \\
\hline $\mathrm{Rc}(\%)$ & 81.22 & 81.22 & 0.44 \\
\hline $\mathrm{G}^{\prime}(\mathrm{Pa})$ & $28.54 \cdot 10^{3}$ & $28.48 \cdot 10^{3}$ & $2.81 \cdot 10^{3}$ \\
\hline $\mathrm{G}^{\prime}(\mathrm{Pa})$ & $9.79 \cdot 10^{3}$ & $9.77 \cdot 10^{3}$ & $0.90 \cdot 10^{3}$ \\
\hline $\mathrm{G}^{*}(\mathrm{~Pa})$ & $30.17 \cdot 10^{3}$ & $30.11 \cdot 10^{3}$ & $2.95 \cdot 10^{3}$ \\
\hline $\tan \delta$ & $345.50 \cdot 10^{-3}$ & $345.50 \cdot 10^{-3}$ & $3.44 \cdot 10^{-3}$ \\
\hline
\end{tabular}

As it can be seen from Table 5, experimentally, the values obtained for dough rheological characteristics are in good agreement with the predicted values, revealing a satisfactory result.

\section{Conclusion}

The physico-chemical characteristics of the refined wheat flour are changed by the addition of GSF at different levels and particle sizes. The increase of the protein and ash contents and higher alpha-amylase activities found in the composite flours can lead to improved chemical characteristics of bread.

Response surface methodology represents an adequate tool to reveal the mechanism remarked in the composite flour dough as well as to optimize the amount of grape seed flour and particle size in the recipe based on refined wheat flour.

This study highlighted that the small particle size at 3.01\% GSF replacement level in refined wheat flour could be used in order to obtain grape seeds-wheat composite flour with the best dough rheological properties. Further studies are needed to evaluate the sensorial acceptance of this novel product.

Acknowledgements. This work was supported by a grant of the Romanian National Authority for Scientific Research and Innovation, CNCS/CCCDI - UEFISCDI, project number PN-III-P2-2.1-BG2016-0136, within PNCDI III. 


\section{References}

1. Quiles A., Campbell G.M., Struck S., Rohm,H., Hernando I. (2018), Fiber from fruit pomace: A review of applications in cereal-based products, Food Reviews International, 34(2), pp.162-181.

2. Šrporin M., Avbelj M., Kovač B., Možina S.S. (2018), Quality characteristics of wheat flour dough and bread containing grape pomace flour, Food Science and Technology International, 24(3), pp. 251-263.

3. Meral R., Doğan I.S. (2013), Grape seed as a functional food ingredient in bread-making, International Journal of Food Sciences and Nutrition, 64, pp. 372-379.

4. Boudová Pečivová P., Kráčmar S., Kubáň V., Mlček J., Juríková T., Sochor J. (2014), Effect of Addition of Grape Seed Flour on Chemical, Textural and Sensory Properties of Bread Dough, Mitteilungen Klosterneuburg, 64, pp. 114-119.

5. Brenes A., Viveros A., Chamorro S., Arija, I. (2016), Use of polyphenol-rich grape byproducts in monogastric nutrition. A review, Animal Feed Science and Technology, 211, pp. $1-17$.

6. Gubsky S., Labazov M., Samokhvalova O., Grevtseva N., Gorodyska O. (2018), Optimization of extraction parameters of phenolic antioxidants from defatted grape seeds flour by response surface methodology, Ukrainian Food Journal, 7(4), pp. 627-639.

7. Iuga M., Ropciuc S., Mironeasa S. (2017), Antioxidant activity and total phenolic content of grape seeds and peels from Romanian varieties, Food and Environment Safety Journal, 16(4), pp. 276-281.

8. Mironeasa S. (2017), Valorization of secondary products from wine making, Performantica Publishing House, Iasi, Romania.

9. Rockenbach I.I., Jungfer E., Ritter C., Santiago-Schübel B., Thiele B., Fett R., Galensa R. (2012), Characterization of flavan-3-ols in seeds of grape pomace by CE, HPLC-DAD-MSn and LC-ESI-FTICR-MS, Food Research International, 48(2), pp. 848-855.

10. Karaman S., Karasu S., Tornuk F., Toker O.S., Geçgel U., Sagdic O., Ozcan N., Gül O. (2015), Recovery potential of cold press byproducts obtained from the edible oil industry: physicochemical, bioactive, and antimicrobial properties, Journal of Agricultural and Food Chemistry, 63(8), pp. 2305-2313.

11. Zhou T., Li Q., Zhang J., Bai Y., Zhao, G. (2010), Purification and characterization of a new $11 \mathrm{~S}$ globulin-like protein from grape (Vitis vinifera L.) seeds, European Food Research and Technology, 230, pp. 693-699.

12. Iuga M., Codină G.G., Mironeasa S., Oroian M. (2017), Amino acid composition of grape seed and peels from grape pomace, The 16th International Symposium prospects for the 30th Millennium Agriculture, Cluj-Napoca, Romania, September 28-30, published in Book of abstracts, 4, pp. 381.

13. Tseng, A., Zhao, Y., (2013), Wine grape pomace as antioxidant dietary fibre for enhancing nutritional value and improving storability of yogurt and salad dressing, Food Chemistry, 138(1), pp. 356-365.

14. Amariei S., Norocel L., Pădureț S., Gutt G., (2018), Effect of grape seed flour on the quality of summer salami, Journal of Food Processing and Preservation, 42(5), pp. e13601.

15. Aksoylu Z., Çağindi Ö., Köse E. (2015), Effects of blueberry, grape seed powder and poppy seed incorporation on physicochemical and sensory properties of biscuit, Journal of Food Quality, 38, pp. 164-174.

16. Mironeasa S., Codină G. G., Mironeasa C. (2016), Optimization of wheat-grape seed composite flour to improve alpha-amylase activity and dough rheological behavior, International Journal of Food Properties, 19(4), pp. 859-872.

17. Tietze S., Jekle M., Becker T. (2016), Possibilities to derive empirical dough characteristics from fundamental rheology, Trends in Food Science \& Technology, 57, pp. 1-10. 
18. Mironeasa S., Codină G.G., Mironeasa C. (2012), The effects of wheat flour substitution with grape seed flour on the rheological parameters of the dough assessed by Mixolab, Journal of Texture Studies, 43, pp. 40-48.

19. Iuga M., Mironeasa S., Zaharia D., Ropciuc S., Mironeasa C. (2017), Effects of grape seeds flour addition on wheat flour dough rheological properties, International Multidisciplinary Scientific GeoConference: SGEM: Surveying Geology \& mining Ecology Management, 17, pp. 209-216.

20. Iuga M., Mironeasa C., Mironeasa S. (2019), Oscillatory rheology and creep-recovery behaviour of grape seed-wheat flour dough: effect of grape seed particle size, variety and addition level, Bulletin of University of Agricultural Sciences and Veterinary Medicine ClujNapoca. Food Science and Technology, 76(1), pp. 40-51.

21. Sanz-Penella J.M., Tamayo-Ramos J.A., Sanz Y., Haros M. (2009), Phytate reduction in bran-enriched bread by phytase-producing bifidobacteria, Journal of Agricultural and Food Chemistry, 57(21), pp. 10239-10244.

22. Kurek M., Wyrwisz J., Piwińska M., Wierzbicka A., (2016), The effect of oat fibre powder particle size on the physical properties of wheat bread rolls, Food Technology and Biotechnology, 54(1), pp. 45-51.

23. Martínez M.M., Díaz Á., Gómez M. (2014), Effect of different microstructural features of soluble and insoluble fibres on gluten-free dough rheology and bread-making, Journal of Food Engineering, 142, pp. 49-56.

24. Mironeasa S., Iuga M., Zaharia D., Dabija A., Mironeasa C., (2017), Influence of particle sizes and addition level of grape seeds on wheat flour dough rheological properties, International Multidisciplinary Scientific GeoConference: SGEM: Surveying Geology \& mining Ecology Management, 17, pp. 265-272.

25. Dhingra D., Mona M., Rajput H., Patil R.T. (2012), Dietary fibre in foods: a review, Journal of Food Science and Technoogy, 49, pp. 255-266.

26. Hadnadev T.D., Torbica A., Hadnađev M. (2011), Rheological properties of wheat flour substitutes/alternative crops assessed by Mixolab, Procedia Food Science, 1, pp. 328-334.

27. Tronsmo K.M., Magnus E.M., Baardseth P., Schofield J.D., Aamodt A., Færgestad E.M. (2003), Comparison of small and large deformation rheological properties of wheat dough and gluten, Cereal Chemistry, 80(5), pp. 587-595.

28. Khatkar B.S., Schofield J.D. (2002), Dynamic rheology of wheat flour dough. II. Assessment of dough strength and bread-making quality, Journal of the Science of Food and Agriculture, 82, pp. 823-826.

29. Skendi A., Papageorgiou M., Biliaderis C.G. (2009), Effect of barley $\beta$-glucan molecular size and level on wheat dough rheological properties, Journal of Food Engineering, 91, pp. 594-601.

30. Martínez M.M., Díaz Á., Gómez M. (2014), Effect of different microstructural features of soluble and insoluble fibres on gluten-free dough rheology and bread-making, Journal of Food Engineering, 142, pp. 49-56.

31. Mirsaeedghazi H., Emam-Djomeh Z., Mousavi S.M.A. (2008), Rheometric measurement of dough rheological characteristics and factors affecting it, International Journal of Agriculture and Biology, 10, pp. 112-119.

32. Tuncil Y.E., Jondiko T., Castell-Perez M.E., Puerta-Gomez A.F., Awika J.M. (2016), Small deformation rheological properties of dough are useful tool to predict the effects of modest sodium reduction on flour tortilla quality, LWT-Food Science and Technology, 68, pp. 329333.

33. Steffe J. (1996), Rheological methods in food process engineering, Freeman Press, Michigan, USA.

34. Wu C.J., Hamada M.S. (2011), Experiments: Planning, analysis, and optimization (Vol. 552), Hoboken, New Jersey: John Wiley \& Sons. 
35. Drakos A., Kyriakakis G., Evageliou V., Protonotariou S., Mandala I., Ritzoulis C. (2017), Influence of jet milling and particle size on the composition, physicochemical and mechanical properties of barley and rye flours, Food Chemistry, 215, pp. 326-332.

36. Mironeasa S. (2013), Grape seeds: studies and research, PIM Publishing House, Iasi, Romania.

37. Mironeasa S., Mironeasa C., Codină G.G. (2010), Evaluation of Mineral Element Content in Grape Seed and Defatted Grape Seed, Food and Environment Safety, IX, pp. 53-60.

38. Dhen N., Román L., Ben I., Mario R., Martínez M., Garogouri M., Gómez M. (2016), Particle size distribution of soy flour affecting the quality of enriched gluten-free cakes, LWT-Food Science \& Technology, 66, pp. 179-185.

39. Kiszonas A. M., Engle D.A., Pierantoni L.A., Morris C.F. (2018), Relationships between Falling Number, $\alpha$ - amylase activity, milling, cookie, and sponge cake quality of soft white wheat, Cereal Chemistry, 95(3), pp. 373-385.

40. Sundarram A., Murthy T.P.K. (2014), $\alpha$-amylase production and applications: a review, Journal of Applied \& Environmental Microbiology, 2(4), pp. 166-175.

41. Păucean A., Man S.M., Socaci S.A. (2016), Wheat germ bread quality and dough rheology as influenced by added enzymes and ascorbic acid, Studia Universitatis Babes-Bolyai, Chemia, 2(61), pp. 103-118.

42. Mohammed I., Ahmed A.R., Senge B. (2014), Effects of chickpea flour on wheat pasting properties and bread making quality, Journal of Food Science and Technology, 51 (9), pp. 1902-1910.

43. Sivaramakrishnan H.P., Senge B., Chattopadhyay P.K. (2004), Rheological properties of rice dough for making rice bread, Journal of Food Engineering, 62(1), pp. 37-45.

44. Abebe W., Ronda F. (2014), Rheological and textural properties of tef [Eragrostis tef (Zucc.) Trotter] grain flour gels, Journal of Cereal Science, 60(1), pp. 122-130.

45. Brockmole C.L., Zabik M.E. (1976), Wheat bran and middlings in white layer cakes, Journal of Food Science, 41, pp. 357-360.

46. Song Y., Zheng Q. (2007), Dynamic rheological properties of wheat flour dough and proteins, Trends in Food Science \& Technology, 18(3), pp. 132-138.

47. Ahmed J. (2014), Effect of particle size and temperature on rheology and creep behavior of barley $\beta-\mathrm{d}$-glucan concentrate dough, Carbohydrates and Polymers, 111, pp. 89-100.

48. Mironeasa S., Iuga M., Zaharia D., Mironeasa C. (2019), Rheological analysis of wheat flour dough as influenced by grape peels of different particle sizes and addition levels, Food and Bioprocess Technology, 12(2), pp. 228-245. 